\title{
The Polish Blood Transfusion Service - Quality, Guidelines, Laws, Selected Topics of Interest and Future Challenges
}

\author{
Jolanta Antoniewicz-Papis Magdalena Letowska \\ Institute of Hematology and Transfusion Medicine, Warsaw, Poland
}

\section{Key Words}

Blood transfusion centers · Quality standards

\section{Summary}

The activity of the Polish Blood Transfusion Service (BTS) is based on the Public Blood Transfusion Service Act sanctioned by the Polish Parliament. There are 21 regional Blood Transfusion Centers (BTCs), 1 Military BTC and 1 BTC of the Ministry of Internal Affairs. The Institute of Hematology and Transfusion Medicine (IHTM) is responsible for issuing guidelines for blood transfusion medicine. All BTCs must have an accreditation from the Ministry of Health. Poland has a national system of hemovigilance. Hospitals are obliged to immediately report all posttransfusion complications and 'near-miss' events. Immunological, viral, bacterial as well as TRALI (transfusion-associated lung injury) reactions are supervised by the IHTM. Qualification improvement and personnel training are priorities of the Polish BTS.

\section{National Transfusion Regulations and Guidelines}

The activity of the Polish Blood Transfusion Service (BTS) is based on the Public Blood Transfusion Service Act sanctioned by the Polish Parliament in 1997 and amended in November 2003 according to the recommendations of Directive 2002/98/EC. The activity of the BTS in Poland is supervised by the Polish Ministry of Health. The amended Public Blood Transfusion Service Act of 2002 implemented specific legal regulations concerning: i) procedures for external BTS au-

\author{
Schlüsselwörter \\ Bluttransfusionszentren · Qualitätsstandards
}

\section{Zusammenfassung}

Die Arbeit des polnischen Bluttransfusionsdienstes (BTS) basiert auf dem nationalen Bluttransfusionsdienst-Gesetz, das durch das polnische Parlament erlassen wurde. In Polen gibt es 21 regionale Bluttransfusionszentren (BTZs), eine militärisches BTZ und ein BTZ im Innenministerium. Das Institut für Hämatologie und Transfusionmedizin (IHTM) ist für die Erstellung von Richtlinien für die Transfusionsmedizin verantwortlich. Alle BTZs müssen vom Gesundheitsministerium akkreditiert sein. Polen verfügt über ein nationales Hämovigilanzsystem. Die Kliniken sind gehalten, sämtliche postransfusionellen Komplikationen und Beinahe-Fehler sofort zu melden. Immunologische, virale und bakterielle Reaktionen sowie Fälle von TRALI (transfusionsassoziierte akute Lungeninsuffizienz) werden vom IHTM betreut. Qualitätsverbesserung und Training des Personals sind Leitziele des polnischen BTS.

dits, ii) professional qualification criteria for personnel employed in public blood transfusion services, iii) training programs for nurses involved in transfusion of blood and blood components, iv) health criteria for donor candidates and donors of blood and blood components, v) procedures for management of blood donor register, vi) prices of blood and blood components (annually updated), vii) organization of blood transfusion treatment in public health service units for patients with indications for treatment with blood and blood components.

\begin{tabular}{ll}
\hline KARGER & $\oplus$ 2006 S. Karger GmbH, Freiburg \\
Fax +497614520714 & Accessible online at: \\
$\begin{array}{l}\text { E-mail Information@Karger.de } \\
\text { www.karger.com }\end{array}$ & www.karger.com/tmh
\end{tabular}

\section{KARGER}

www.karger.com
Jolanta Antoniewicz-Papis, PhD

Institute of Hematology and Transfusion Medicine

Indiry Gadhi 14, 02-779 Warsaw

Tel. +48 22 3496-381, Fax -376

E-mail jpapis@ihit.waw.pl 
Fig. 1. Distribution of regional BTC on the territory of Poland.
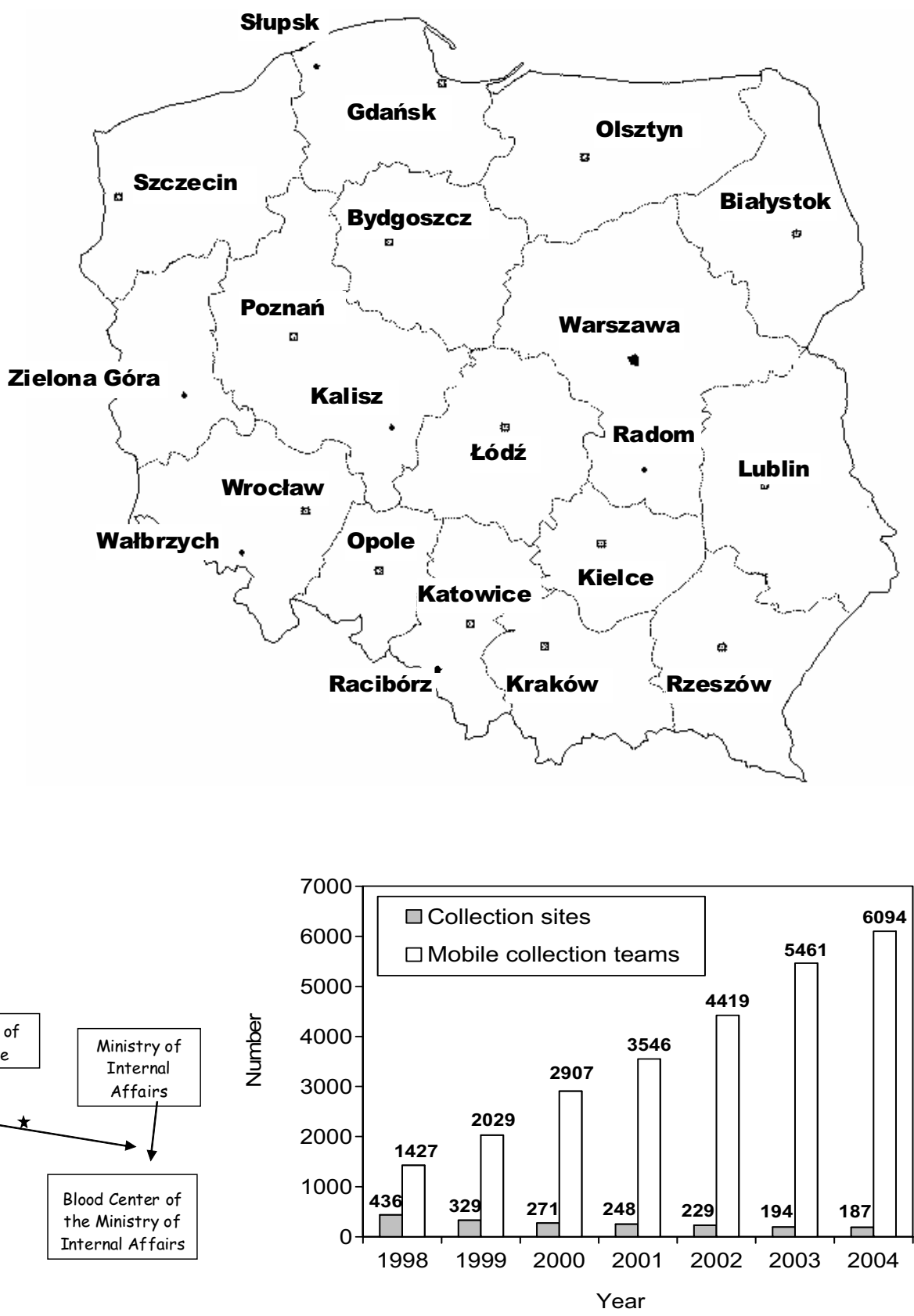

Fig. 3. Tendencies and changes in the structure of blood collection.

tionation. Regional centers are units independent of hospital structures.

The regional centers have satellite collection sites the number of which decreases every year in favor of mobile blood collection units (fig. 3). In this country of approximately 38 million inhabitants, approximately 1,000,000 donations are collected annually. The donation index is about 25 donations per 1,000 inhabitants. Approximately 1,600,000-1,800,000 blood and blood component transfusions are performed annually. Less than $1 \%$ are whole blood transfusions. The task of public blood transfusion centers is to supply hospital patients with safe blood and blood components. Blood safety is guaranteed 
by careful donor and donor candidate selection according to Directive recommendations and Ministry of Health regulations. The IHTM is responsible for issuing guidelines for the collection, testing, processing, storage and distribution of blood and blood components. These guidelines are currently updated to fulfill the demands of international regulations and adaptation to national standards.

\section{Quality Assurance and Accreditation}

The Quality Control System was implemented in Poland in the 1990s and has gradually expanded its activity to be recently transformed into a Quality Assurance System. At present, each regional BTC has its Quality Assurance Department with a wide scope of responsibility and activity. According to current regulations, the Head of Quality Assurance is subordinate to the Director of the regional BTC and responsible for its transfusion activity. Among others, the tasks of the Quality Assurance Department include supervision of training programs, hemovigilance, and participation in processes of resolving post-transfusion complications. Quality assurance includes quality control. Every blood-collecting facility is obliged to develop and implement its own quality assurance procedures based on guidelines/recommendations issued by the IHTM which is the supervising authority for both the regional BTC with its satellite collection sites as well as hospital blood banks and laboratories that perform testing for transfusion medicine on the whole territory supervised by the regional BTC. Supervision consists of external audits of all facilities dealing with blood collection, organization of systematic personnel training programs, as well as support in situations demanding implementation of corrective measures. Corrective measures are launched immediately once deviations are found. Methods of introducing corrective measures are described in Standard Operating Procedures (SOPs). To reduce the risk of errors during collection, testing, processing and distribution of blood and blood components, various preventive actions are undertaken, including obligatory training for all personnel within their routine performance as well as in the activity of the center as whole.

It is of profound importance for quality assurance in a regional BTC to determine its critical points and recommend that they are in the focus of attention in routine activity. Depending on the significance of deviations, the scope of corrective measures is either limited to only the one regional BTC or includes regional centers in the whole country. In the latter case, corrective activities are supervised by the IHTM. The IHTM is also involved when deviations in the use of disposable equipment or viral and serological testing found in one regional center concern several other BTCs as well. Resolving procedures are then launched in cooperation with the manufacturer. To eliminate human error, it is recommended to attain as high a degree of automation as possible. Nowadays, each center has its com- puter system that registers all activities of the center, from donor registration to blood or blood component distribution for clinical use or fractionation. Results of laboratory tests and activities related to blood collection and processing are automatically introduced into the computer system.

Every blood collecting facility is subjected to an external audit at least once every 2 years. Audits are performed by the IHTM or the MPI. Blood and blood component collection, testing processing and distribution activity are only possible on the condition that the facility has been granted accreditation after having passed external audits by the IHTM and applied for such accreditation to Ministry of Health. No accreditation is granted if critical errors are found during the external audit. Numerous regional centers have also been granted ISO 2001 certificates, and several others will acquire such certificates in the near future. The necessity to adapt to the ISO standards has resulted in significant improvement in the quality of performance in blood-collecting facilities, which in practice means more safety for both donors and recipients. However, efforts never cease to improve the quality and methods of performance.

\section{Quality and Hemovigilance}

Higher quality of blood components calls for modern equipment, better reagents and more effective methods as well as higher personnel qualifications. The cost of improvement is high. Prices of blood and basic blood components are regulated by the Polish law and calculated by the Polish Ministry of Health on the basis of costs borne by individual centers. Prices are set for 1 year and then verified annually according to the current costs. The prices for 2006 are presented in table 1 . Regional centers are partly financed from the central budget, and this financial support is not included in the price of blood paid by hospitals.

For several years now, Poland has had a national system of hemovigilance. The Public Blood Transfusion Service Act of 1997 has put an obligation on hospitals to report all adverse reactions. Such reports are subjected to analysis in the regional center and then reported to the IHTM. Since 2005, 'nearmiss' events are also reported by hospitals. In addition, data on complications during blood donation are collected and subjected to analysis. Data on the frequency of viral infections in blood donors are reported by all blood collecting facilities. Hospitals are obliged to immediately report to the regional BTC all post-transfusion complications or 'near-miss' errors, as well as to implement a strictly defined resolving procedure clearly defined by Polish guidelines. After the complication is resolved and categorized, it is reported to the IHTM where data from the whole country are collected. If the problem cannot be resolved in the regional center, the IHTM takes over. 894 adverse reactions were reported in 2004 , equating to 9/10,000 donations. Complications were related to transfusions 
Table 1. Current prices (2006) for basic blood components in Poland

\begin{tabular}{lcc}
\hline Blood component & Price, PLN & Approximate price in EUR \\
\hline Whole blood (1 unit) & 220 & 55 \\
Red blood cell concentrate (1 unit ) & 125 & 32 \\
Fresh frozen plasma (1 unit ) & 90 & 23 \\
Platelet concentrates: recovered (1 unit) & 60 & 15 \\
Apheresis platelet concentrate (1 donation) & 900 & 225 \\
Granulocyte concentrate (1 unit) & 1,250 & 313 \\
\hline
\end{tabular}

Table 2. Frequency of post-transfusion adverse reactions per number of transfusion events in total Poland

Table 3. Severity of adverse reactions

Table 4. Relation of adverse reaction with transfusion

\begin{tabular}{lr}
\hline Imputability & $\%$ \\
\hline 0. no relationship & 22 \\
1. possible & 47 \\
2. likely & 22 \\
3. sure & 9 \\
\hline
\end{tabular}

of the following blood components: red blood cell concentrates $(84.4 \%)$, platelet concentrates $(9.8 \%)$, plasma $(4.8 \%)$ The numbers of specific adverse reactions are presented in table 2 . Their severity in recipients is presented in table 3 . The determined association with transfusion of such adverse reactions is presented in table 4.

The Polish BTS performs in cooperation with numerous organizations and institutions dealing with hemovigilance.

\section{Management of Post-Transfusion Complications}

The majority of immunological post-transfusion complications can be eliminated through very careful testing performed prior to transfusion. That is why diagnosis of factors that cause such complications is of the utmost importance. Regional BTCs and the IHTM supervise the activity of all laboratories that perform immunological testing for transfusion medicine. Consultation tests for hospitals are performed in regional centers, and the IHTM is involved in highly specialized testing. The IHTM also participates in multicenter scientific studies, related, among others, to the assessment of risks of post-transfusion complications and transmission of viral infection.

Despite very careful donor selection, there always exists the risk of infections transmitted through donated blood. It is therefore extremely important to properly educate donors and donor candidates. In many schools, enterprises, colleges and universities, special lecture programs are organized on blood donation. During such meetings, a lot of time is devoted to the risk of viral and bacterial infections of donors and transmission of such infections to recipients. Apart from this donor education activity and careful donor selection, the personnel involved in blood collection must be appropriately trained. Disinfection of the puncture site is the critical point in blood collection, therefore it is necessary to adhere to all guidelines issued by the IHTM. In Poland, as a result of appropriate operating procedures, bacterial post-transfusion complications are rare - approximately 1/120,000 transfusions. Bacterial complications related to transfusions of platelet concentrates are practically nonexistent.

Therapeutic use of blood and blood components is still burdened with transmission of viral infections. To reduce the risk, donors are serologically tested for human immunodeficiency virus (HIV) and hepatitis $\mathrm{B}(\mathrm{HBV})$ and $\mathrm{C}$ virus (HCV) at every blood or blood components donation. The frequency of HIV detection in Polish blood donors is not high and during the last years varied from 0.0015 to $0.004 \%$ (table 5). Therefore, the risk of HIV infection is relatively low, at less than 1 per $10^{6}$. In Poland, during the past 9 years, no incident of HIV infection of recipients through blood or blood components has been reported. The frequency of carriers of hepatitis B and C markers among donors and donor candidates in Poland is higher than in other Western European countries. In 2003, it was $0.12 \%$ for $\mathrm{HBV}$ and $0.17 \%$ for $\mathrm{HCV}$. The still prevailing risk of viral infection transmission, has been the reason for the introduction (as of January 1, 2000) of obligatory HCV RNA testing by polymerase chain reaction (PCR) of plasma for fractionation. On January 1, 2002, obligatory HCV RNA test- 
Table 5. Detection frequency of viral markers per total number of donations*

\begin{tabular}{lllllll}
\hline \multicolumn{7}{c}{ Frequency of viral markers, \% } \\
\cline { 2 - 7 } & 1999 & 2000 & 2001 & 2002 & 2003 & 2004 \\
\hline HBV & 0.16 & 0.17 & 0.13 & 0.12 & 0.13 & 0.13 \\
HCV & 0.19 & 0.22 & 0.17 & 0.17 & 0.14 & 0.16 \\
HIV & 0.0030 & 0.0040 & 0.0027 & 0.0020 & 0.0020 & 0.0020 \\
\hline
\end{tabular}

*Total for confirmed seropositive regular donors (reactive in a screening test and positive in confirmatory test) and for seropositive new donors (reactive only in a screening test - ELISA). ing for each donation was introduced, and since January 1, 2005 testing for HBV DNA and HIV RNA is also obligatory. At present, testing is performed in single donations (transcription-mediated assay) or in mini-pools of 24 samples (PCR). In plasma for fractionation, HIV RNA testing was introduced on August 1, 2004. Nucleic acid testing has significantly reduced the risk of infection transmission.

Since 2000, special attention has been paid to TRALI diagnostics. All clinical symptoms of acute breathing disorders related to transfusion of blood components during transfusion or within $6 \mathrm{~h}$ of transfusion are reported by hospitals to regional BTCs. At first, the reports were in form of a special questionnaire, now the Ministry of Health has approved a special report form for adverse reactions. Blood samples from donor and recipient are then tested. HLA class I and II antibody testing is performed by ELISA, lymphocytotoxicity test (LCT) and monoclonal antibody immobilization of lymphocytes antigen (MAILA). Granulocyte antibodies are tested via granulocyte agglutination test (GAT), granulocyte immunofluorescence test (GIFT) and monoclonal antibody immobilization of granulocyte antigen (MAIGA). All ELISA-detected antibodies are confirmed with immunofluorescent test with lymphocytes (FlowPRA), and their specificity is determined. Within 5 years, 34 cases of dyspnea related to blood transfusion were reported. TRALI was detected in 11 cases, and in 15 cases TRALI was determined as likely. The trace-back procedure was implemented, and no TRALI incidents during previous transfusions were confirmed. Moreover, more than 1,000 random donors were tested for HLA antibodies. In $10 \%$ of the women, antibodies were confirmed, whereas no antibodies were detected in any of the men. TRALI was detected only in 1 recipient who had been given blood from the same group type. Permanent deferral of donors with antibodies is still under discussion, but it is recommended not to transfuse plasma from such donors.

\section{Contingency Plans}

In a world dominated by wars and disasters, the demand for blood and blood components is ever growing, but there may be difficulties related to collection. In Poland, there are regulations which clearly determine the obligations of all services engaged in such events. In every regional city, there exist crisis headquarters subordinated to national headquarters. Regional BTCs have developed action plans for crisis situations. Experience indicates that when disaster strikes, large numbers of volunteers and repeated blood donors flock to the regional centers, resulting in blood collection significantly exceeding the immediate demand. Moreover, additional blood collection sites can quickly be set up to increase the quantity of collected blood. That is exactly what happened in the winter of 2006, during the collapse of the Katowice Trade Center. Blood collection for the victims was organized throughout the country. As result, the demand for blood was easily satisfied. The Polish society is extremely sensitive to such appeals and reacts immediately. A similar reaction was reported in the USA after the terrorist attacks on the World Trade Center in 2001.

Epidemics of infectious diseases are more serious and call for a special program. The most important aspect here is the cooperation between all services engaged in rescue operations. In the very near future, the Polish BTS will develop a system of procedures for a flu pandemic in Europe. The biggest problem is the restriction of the activity of regional BTCs due to personnel and donor shortage. It is therefore necessary to consider changes and personnel shifts for more effective organization and contact with clinics. Clinics on the other hand, need to be instructed to use less blood components and reduce the number of elective surgical procedures.

\section{Challenges for the Polish BTS}

Continuous improvement of the quality of blood and blood components related to safety is the greatest challenge of a contemporary blood transfusion service. That is why so much attention is being paid to the development of viral marker detection. Nowadays, one of the most important goals of the Polish BTS is to set up a National Register of Blood Donors. The aim is to collect in one place all the relevant information regarding donors. It is therefore planned to create a central data center for the BTS, which will facilitate information exchange between units of the public health service. In future, it will serve as a reference center for other public health service facilities and public registers. Hemovigilance is one of the most important tasks set up by the Directive 2002/98/EC. This task 
can be fulfilled by creating an efficient system of automatic data transfer, which allows for a step-by-step follow-up of blood donation, from the moment of donor registration, through testing, blood collection, processing, distribution to hospitals and patients.

In order to attract new donors and to maintain the highest possible number of regular donors, it is necessary to organize promotions. A professional website for donors may be helpful in this respect. Such actions are planned in combination with a donor register. Improvement of qualifications and constant training of personnel involved in blood and blood component collection, testing, processing and use is one of the priorities of the BTS. One of the crucial aspects is to stress the importance of blood transfusion to every hospital ward, to improve supervision and control, and to create opportunities for analyzing the use of blood and blood components. Every hospital where transfusions are performed has a hospital transfusion committee. In smaller hospitals, this activity is supervised by a doctor responsible for blood management. The task of the committee, among others, is to review indications for transfusion, to analyze the usage of blood and blood components, to evaluate transfusion methodology, post-transfusion complications, 'near-miss' events, and to prepare internal training programs for doctors and nurses as well as to participate in planning the supply of blood and blood components. Personnel should be trained to perform these tasks in accordance with the constantly modernized methods of transfusion practice.

One of the major challenges of the Polish BTS is the constant promotion of volunteer blood donation and new donor recruitment. This is the sphere of activity of regional BTCs but also of the Polish Red Cross and other non-governmental organizations which act in close cooperation with the IHTM and the regional centers. They participate in all major events promoting volunteer blood donation. The Krewniacy Foundation, for example, has organized a widespread billboard, radio and television promotion campaign to secure funds for a special blood collection bus. This foundation is managed by people who for various reasons cannot be donors themselves but are fully aware of the importance of volunteer blood donation and help to promote it. The Polish BTS perpetually strives to improve the safety of blood and blood components for clinical use. Representatives of the IHTM are active in international organizations and together with representatives of other European countries develop programs to solve problems that are a constant challenge to blood transfusion services worldwide. 